
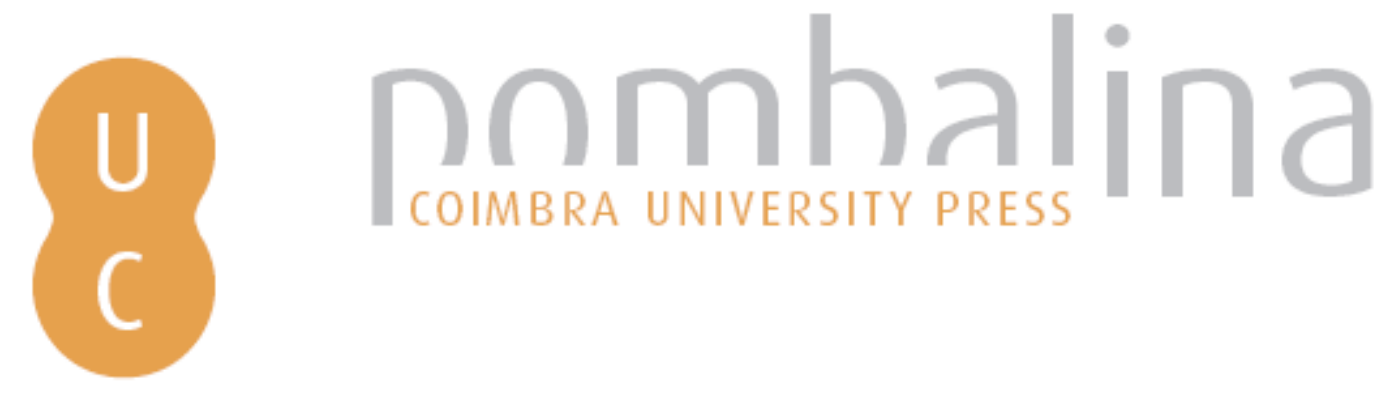

\title{
As minas de ouro das Américas, novos espaços para a imaginação científica
}

Autor(es): $\quad$ Mariano, Alexandra de Brito

Publicado por: Associação Portuguesa de Estudos Clássicos; Imprensa da

URL

persistente: URI:http://hdl.handle.net/10316.2/31821

DOI: $\quad$ DOI:http://dx.doi.org/10.14195/978-972-98142-2-8_11

Accessed : $\quad$ 26-Apr-2023 08:22:11

A navegação consulta e descarregamento dos títulos inseridos nas Bibliotecas Digitais UC Digitalis, UC Pombalina e UC Impactum, pressupõem a aceitação plena e sem reservas dos Termos e Condições de Uso destas Bibliotecas Digitais, disponíveis em https://digitalis.uc.pt/pt-pt/termos.

Conforme exposto nos referidos Termos e Condições de Uso, o descarregamento de títulos de acesso restrito requer uma licença válida de autorização devendo o utilizador aceder ao(s) documento(s) a partir de um endereço de IP da instituição detentora da supramencionada licença.

Ao utilizador é apenas permitido o descarregamento para uso pessoal, pelo que o emprego do(s) título(s) descarregado(s) para outro fim, designadamente comercial, carece de autorização do respetivo autor ou editor da obra.

Na medida em que todas as obras da UC Digitalis se encontram protegidas pelo Código do Direito de Autor e Direitos Conexos e demais legislação aplicável, toda a cópia, parcial ou total, deste documento, nos casos em que é legalmente admitida, deverá conter ou fazer-se acompanhar por este aviso.

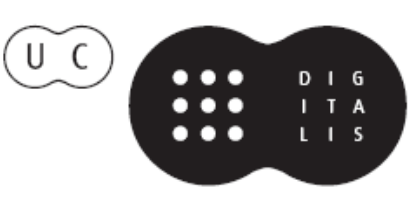




\section{Espaços e Paisagens}

\section{Antiguidade Clássica e Heranças Contemporâneas}

Vol. Il Línguas e Literaturas. Idade Média. Renascimento. Recepção

Francisco de Oliveira, Cláudia Teixeira, Paula Barata Dias (Coords.)

IMPRENSA DA UNIVERSIDADE DE COIMBRA 


\title{
AS MINAS DE OURO DAS AMÉRICAS NOVOS ESPAÇOS PARA A IMAGINAÇÃO CIENTÍFICA
}

\author{
Alexandra de Brito Mariano \\ Universidade do Algarve \\ amariano@ualg.pt
}

\begin{abstract}
By the mid seventeen hundreds, Brazilian José Basílio da Gama wrote Brasilienses aurifodinae ([Roma], c. 1762), a Latin poem included in a long tradition of didactic poetry, which at that time would make itself evident in texts, written both in Europe, and the New World, referring to the subject of gold, and its mining. To support this are provided examples such as the Aurum (Paris, 1703) by French Jesuit Antoine le Febvre, the Metallurgicon (Tyrnau, 1748), by Hungarian Jesuit Joseph Bartakovics, and the Rusticatio mexicana (Bolonha, 1782) by Rafael Landivar's (SJ).

Evidence is thus given for the fact that didactic poetry persisted throughout the ages, depicting itself in poetic production with various linguistic uses and diverse levels of expanding scientific detail, but with an ever present didactic intent; they can be viewed today as a set of relevant examples of the Society of Jesus' spirit of scientific inquiry, as well of historic commitment to gold lore.
\end{abstract}

Keywords: Americas, History of Science, Mining, Neo-Latin, Poetry, Society of Jesus.

Palavras-chave: Américas, Companhia de Jesus, História da Ciência, Mineração, Neolatim, Poesia.

Enquanto durou o Setecentos, um significativo conjunto de jesuítas dedicou-se à elaboração de poemas didácticos sobre os mais variados assuntos, de que nos convém destacar aqueles que abordam temas de cariz científico. Usaram, para esse efeito, predominantemente o Latim; proficientemente aprendido durante a formação nos Colégios da Companhia, e que detinha ainda o estatuto de língua franca da erudição e da circulação do conhecimento, neste período em que desponta o espírito científico que hoje se estabeleceu como paradigma dominante da racionalidade.

Françoise Waquet destaca, com efeito, que apesar do uso das línguas vernaculares se ter tornado predominante, o Latim foi a língua por excelência da difusão do conhecimento no mundo ocidental civilizado até meados do século XVIII. ${ }^{1} \mathrm{O}$ que se nos afigura como trabalho árduo, era então entendido

\footnotetext{
${ }^{1}$ Cf. F. Waquet 2002: 81-2.
} 
por muitos como uma prática recreativa, ${ }^{2}$ que proporcionava sentimentos de pertença e identificação entre os membros de determinados círculos, de marcado carácter elitista.

Vários destes autores abordaram temas mineralógicos em poemas didácticos, com particular atenção prestada ao ouro, em que é possível encontrar características particulares e interligações poéticas que nos permitem relacioná-los. Convocamos aqui o poema Aurum, da autoria do jesuíta francês Antoine le Febvre, editado em Paris, em 1703 - e que mereceu a atenção do periódico oficial da Companhia ${ }^{3}$ - e o Metallurgicon, poema em dois livros, com apêndices em alemão e húngaro, escrito pelo poeta jesuíta magiar Joseph Bartakovics e publicado em Tirnau em $1748 ;{ }^{4}$ citam-se também dois poemas posteriores, da segunda metade do século XVIII, que demonstram que o interesse pelo ouro não se restringiu ao Velho Mundo. Trata-se do Brasilienses aurifodinae, redigido provavelmente em Roma, por volta de 1762, pelo exjesuíta brasileiro José Basílio da Gama, e da Rusticatio mexicana, da autoria do inaciano guatemalteco Rafael Landivar, que inclui livros sobre a prata e o ouro (livros 7 e 8), com uma primeira edição datada de 1781, em Modena, rapidamente seguida por uma versão revista, publicada em Bolonha em 1782, que utilizamos. ${ }^{5}$

Importa lembrar, antes de mais, alguns elementos biográficos dos poetas em apreço, que permitem compreender melhor o contexto e motivação das suas obras. Comece-se por referir que a informação biobibliográfica acerca de Le Febvre é escassa. Ao certo, sabe-se que nasceu em 1670 em Clairvaux, no Jura francês, e que ensinou humanidades na sua província. Antes de 1703, data da edição do seu poema sobre o ouro, foi chamado a Paris, para leccionar no Colégio Louis-le-Grand, cidade onde morreria a 16 de Setembro de 1737.

Também escasseiam os detalhes sobre Joseph Bartakovics. Nasceu em Szalakuz, na actual Eslováquia, em 1722; foi admitido na corporação jesuítica aos 18 anos. A sua formação foi semelhante à de muitos outros jesuítas: tornou-se professor, leccionou filosofia, história, direito e teologia na que é hoje Kosice, capital da Eslováquia oriental, mas que na altura integrava a Hungria setentrional, onde se estabelecera uma universidade jesuítica em 1657, com faculdades de filosofia, teologia e línguas. Bartakovics faleceu em 1763, na sua cidade natal.

Quanto a Basílio da Gama, nasceu perto da vila de São José do Rio das Mortes, que é a actual cidade de Tiradentes, em 1741. Entrou para o colégio jesuíta do Rio de Janeiro, em 1757, onde concluiu o noviciado e toma votos. Porém, a Companhia de Jesus é extinta por ordem do Marquês de Pombal em 1759, e os seus membros são expulsos de Portugal e das colónias; muitos buscam

${ }^{2}$ A expressão é de Haskell 2003: 6, 210 e 220 n. 120, por exemplo.

${ }^{3}$ Cf. Journal de Trévoux (1703): 1038-1044. Para as citações de Aurum, segue-se a 1. ${ }^{\mathrm{a}}$ edição do poema (vide bibliografia). C. Sommervogel, vol. 3, 577 e 558.

${ }^{4}$ Sobre o autor e a sua obra, ver C. Sommervogel 1890, vol. 1, 962.

${ }^{5}$ Cf. bibliografia. 
protecção nos Estados Pontifícios, como foi o caso deste poeta brasileiro que, durante o curso destes eventos, terá abandonado a Sociedade. É pouco o que se sabe da sua vida posteriormente aos anos de setecentos e sessenta, salvo que se encontra em Lisboa em 1774, empregado na administração pública, e aí vem a falecer em $1795 .{ }^{6}$

Rafael Landívar nasceu na cidade de Santiago de los Caballeros de Guatemala, que hoje é conhecida como Antigua, em 1731 e ali estudou no seminário jesuíta de San Francisco de Borja. Abandonou a Guatemala em 1749, rumando ao México, onde, em Tepotzotlán, ingressou no ano seguinte nos efectivos da Companhia. Em 1761, regressou à Guatemala, de onde foi expulso em 1767, e, depois de um percurso atribulado, fixou-se em Bolonha, onde viria a morrer em 1793. Em vida, ensinou filosofia e retórica; a Rusticatio mexicana foi escrita quando procurou refúgio em Itália, em condições semelhantes ao autor do Brasilienses aurifodinae, anos antes. ${ }^{7}$

Educados no seio da Companhia, estes autores beneficiaram seguramente do contacto com a volumosa correspondência que os membros do Instituto, das casas da Ordem e do Quartel-General trocavam entre si. Essa correspondência constitui um contributo relevante para a circulação e disseminação do conhecimento científico entre as várias províncias da Companhia de Jesus como destaca Steven Harris. ${ }^{8}$ Um tal intercâmbio cultural transcendia, pois, fronteiras geográficas e permite-nos falar duma comunidade internacional de correspondentes que, de forma atenta e industriosa, comunicam entre si o produto da sua erudição.

Com efeito, é possível estabelecer que pelo menos um destes poetas teve conhecimento do poema didáctico acerca do ouro redigido por outro membro da sua ordem - tal é o caso de Basílio da Gama, que refere o poema de Le Febvre, de forma aliás pouco elogiosa, no prefácio do Brasilienses aurifodinae (11. 2-6), para sublinhar as dificuldades que o francês teria ao compor a sua obra, resultantes da sua inexperiência empírica relativamente ao assunto aí abordado.

Basílio da Gama terá eventualmente contactado com o Aurum na biblioteca do Colégio do Rio de Janeiro onde estudou, a fazer fé em Serafim Leite, que refere que a mesma se mantinha permanentementeactualizada, ${ }^{9}$ ou, em alternativa mais provável, em Roma, beneficiando do liberal acesso à informação distribuída pelas excelentes bibliotecas daquela cidade, no convívio com letrados coevos. Apesar desta constituir evidência única dum contacto efectivo entre os autores de que nos ocupamos, são recorrentes, por

\footnotetext{
${ }^{6}$ Informação mais detalhada sobre a biobibliografia deste autor em V. Chaves 2000: 9-11.

${ }^{7}$ Para um estudo recente sobre a vida e obra de Landívar, cf. A. Laird 2006.

${ }^{8}$ S. Harris 2000: 228-229.

${ }^{9}$ Em 1760, teria provavelmente 6000 volumes: livros de ciências sagradas e profanas e as últimas novidades. S. Leite 1945, Vol. 6: 26 ss.
} 
outro lado, nestas obras os tópicos paralelos convergentes no tratamento do precioso metal.

Le Febvre abre o Aurum com uma proposição (vv. 1-4), onde introduz o tema e as preocupações centrais da sua obra, logo seguida da habitual invocação (vv. 4-12, p. 210), com o pedido de inspiração às Piérides, divindades clássicas associadas ao tema; de igual modo no Brasilienses aurifodinae (vv. 5-11), é feita essa invocação para inspiração do poeta, acrescentando-lhe Febo, tradicionalmente associado ao ouro.

No Aurum, o poeta apresenta primeiro um conjunto de territórios conhecidos pela sua abundância em ouro e depois o mito que justifica a sua existência (cf. Aurum, p. 212). É possível estabelecer, neste caso, uma aproximação ao texto Brasilienses aurifodinae onde, após a proposição e invocação, o poeta evoca o mito de Júpiter e Dánae (vv. 12-44) para discorrer depois sobre as várias zonas atingidas pela chuva aurífera do pai dos deuses - completando a lista apresentada por Le Febvre, particularmente no que toca aos rios que a tradição distingue pela presença de areias auríferas (vv. 45-69).

Se para o autor do Aurum, a recens America (v. 27) é apenas uma de várias terras a merecer a sua atenção (Aurum, vv.13-31, pp. 210-211), Bartakovics, pelo contrário, considera unicamente o seu país. Numa clara declaração patriótica, o poeta revela a sua intenção de cantar as riquezas da sua terra natal, em particular a Hungria setentrional, donde provém esse ouro da Panónia cujo fulgor o tocará, antes de percorrer o mundo inteiro (Metallurgicon, p. 2, 10-12).

É também com fervor patriótico que Basílio da Gama refere a América-e o Brasil, em particular - de entre as regiões que nomeia, como a região que mais atingida foi pela divina pluviosidade, tornando-se, portanto, a mais rica em ouro (vv. 69-82).

Na Rusticatio, o foco de atenção de Landívar centra-se em exclusivo nos locais produtores de minério da América espanhola. Pretende apenas cantar as paisagens da sua terra americana, em especial a extensão das cordilheiras da Sierra Madre, desde a Nova Espanha, a sul, até ao seu extremo norte (vv. 15-23). É sob esse território que se escondem os metais preciosos, que só um esforçado trabalho poderá pôr a descoberto (cf. Rusticatio mexicana, 1. 7, vv. 1534, pp. 76-77). A Nova Espanha de Landívar corresponde maioritariamente ao México dos nossos dias, mas incluía, a sul, uma área que hoje se divide pelos territórios da Guatemala e das Honduras. À semelhança do Brasil, o grosso do ouro encontrado na América espanhola era de tipo aluvial, com veios de metal aurífero no interior das minas menos frequentes.

Independentemente da origem atribuída ao metal, a sua génese mitológica é, nalguns dos poemas em apreço, um tópico de destaque incontestável. Por exemplo, no início do Brasilienses aurifodinae, a referência à fábula de Júpiter e Dánae (vv. 12-44); o Aurum começa por recuperar o mito de que o pai dos deuses distribuiu a responsabilidade pela criação de partes da recentemente formada terra aos seus vários filhos (v. 32, p. 211). Depois de conferir o encargo pelos metais aos sete deuses planetários (v. 38, p. 211), foi a Febo, deus sol, a quem coube a criação do ouro, com o contributo do hábil fogo e do fulgor dos 
raios que tem ao seu serviço (vv. 55-61, p. 212).

Note-se, porém, que se a preparação do ouro - com a ajuda da lama e doutras matérias que o poeta deixa por nomear - pertencem ao domínio do mito, bem mais prosaicas são as actividades dos raios trabalhadores. Estes personificam verdadeiros mineiros no seu papel, recorrendo a métodos de eficácia comprovada e chegando a distribuir entre si as tarefas implicadas na mineração, por forma a potenciar uma maior produtividade. No seu trabalho, são-nos descritos divididos em distintos grupos - uns escavando fossos, ${ }^{10}$ outros canais para transporte da água, ${ }^{11}$ outros ainda galerias $-{ }^{12}$ em labor de grande exigência e dureza:

pars limumque parant, habilemque metallo

Materiam: pars multa scrobes, pars multa canales

Effodiunt: fossis fuit acta canalibus unda;

Pars molem subigunt terram, terraeque subactae

Infundunt latices: pars humida granula siccant,

Et fulvum inspirant anima propiore colorem.

Infindunt alii sulcos, perque aspera saxa

Serpere amant: lapsu sese aurea vena sequaci

Insinuat, radioque viam monstrante, pererrat

Sulcatos silices; alios juvat aurea frusta,

Flaventesque globos creta vestire tenaci;

Mollis creta fluit primo, mox igne rigescit

Durior, inclusumque recens lapis obtegit aurum.

Sunt quibus officium est tenues curvare cavernas

Fornicis in morem: quo fornice cara tueri

Pignora, quo pulchros valeant deponere foetus.

Um grupo prepara a lama, e a matéria aconselhável para o metal; um grande grupo escava trincheiras, um grande grupo canais: a água é introduzida e flui por estes canais escavados; outro grupo revolve a terra macia e adiciona-lhe o líquido quando preparado; outro grupo seca os pequenos grãos molhados e insuflalhes a cor fulva com o seu sopro particular. Outros abrem sulcos e gostam de serpentear entre as duras rochas: o veio de ouro insinua-se com um curso tenaz, mostrando o caminho do raio e vagueia por entre a pederneira aberta em sulcos; a outros agrada vestir os pedaços de ouro e as bolas amarelas com o pegajoso barro; a princípio o barro flui suavemente, mas por acção do fogo torna-se mais duro e uma nova pedra esconde o ouro encerrado. Há aqueles cujo trabalho é escavar as estreitas cavernas em forma de abóbada, sob as quais podem guardar os seus queridos tesouros, sob as quais podem dar à luz as suas bonitas crianças.

(Aurum, vv. 61-76, p. 212)

${ }^{10}$ Cf. Brasilienses aurifodinae (vv. 309-317; 832-839; 1363-1368).

${ }^{11}$ Cf. Brasilienses aurifodinae (vv. 753-788; 896-919; 964-980 e 1118-1140).

${ }^{12}$ Cf. Brasilienses aurifodinae (vv. 1141-1334). 
A dureza do trabalho mineiro é aludida no Metallurgicon através do expressão virgiliana labor improbus (Geórg., 1. vv 145ss. Cf. Metallurgicon, p. 25) e fervet opus, que também ocorrem no Aurum e na Rusticatio mexicana, ${ }^{13}$ desenhando um paralelo entre as agruras a que estão sujeitos os mineiros e as actividades dos Ciclopes na caverna visitada por Virgílio (cf. também Aurum, p. 211):

\author{
Mille lacertosi jactant sua brachia Fabri, \\ Fervet opus caeca sub nocte, ingentia pendent \\ Littora, compositis centum suffulta columnis. \\ Noctes, atque dies aeternae funibus Alni \\ Demittuntur: ...
}

Um milhar de esguios mineiros, acenando os braços, trabalham vigorosamente na treva cega, levantando enormes traves ao cimo de centenas de colunas artificiosamente erectas. Enterrados dia e noite, agrilhoados com cadeias de madeira.

(Metallurgicon, p. 42, 20-25)

Na Rusticatio mexicana, o árduo esforço dos mineiros-ciclopes também é colocado em evidência, embora neste caso a separação de tarefas, apesar de não diminuir o desgaste que caracteriza a actividade mineira, poder assegurar alguma especialização e garantir melhores lucros:
Ast ubi congeriem thesauri turba retexit,
Consistit, magnamque fodit sub colle cavernam,
Immensisque vigil sustentat culmina fulcris,
Ne collapsa ruant, pereatque oppressa juventus.
Tunc operam prudens partitur cuique Magister:
Alter enim taedas dextra, lumenque ministrat,
Alter inaccessos proscindit cuspide muros,
Et legit e muris alter salientia frusta
Secernens pingues recto discrimine cautes.
Fossor opes primum, puero praebente lucernam,
Verberat, E multis lapidem quatit ictibus unum.
Saxa gemunt intus teli contusa rigore
Totaque terribili reboat spelunca tumultu.
Ceu quondam Siculi massam Cyclopes ahenam
Aetnaeis valido tractant conamine in antris,
Concutiuntque nigras magno stridore cavernas.

${ }^{13}$ Vide ocorrências: Aurum (v. 109, p. 214) e Rusticatio mexicana (livro 8, v. 39). Basílio da Gama não associa este termo à mineração. Prefere, por exemplo, sumo labore /sumum [...] Laborem /summus labor (vv. 3, 402, 1332, respectivamente); difficili Labori /difficilis labor (vv. 561, 1153); tanti [...] labores / tantisque laboribus (vv. 133 e 1111); intensumque laborem (v. 448); assiduum Laborem (v. 939) e laborem Impensum (vv. 1148-1149). 
Mas quando a multidão desfaz o montão de tesouro, pára e escava debaixo do monte uma grande caverna, atenta sustenta os tectos com grandes pilastras, para que não se desmoronem em ruínas e pereça soterrado o mineiro. Nesse momento, o feitor, prudente, distribui a cada um a sua tarefa: um, com efeito, vigia com a mão os archotes e a luz; o outro rasga com a vara as maciças paredes; e há outro que vai recolhendo os pedaços que saltam das paredes, separando com juízo correcto os ricos escolhos.

O mineiro, à luz que lhe oferece o rapaz, castiga primeiro o veio, batendo a pedra num ponto com múltiplos golpes. As pedras gemem no interior sacudidas pelo rigor da pancada e toda a caverna ressoa com o terrível tumulto. Tal qual como os sículos Ciclopes forjam a massa de bronze com vigorosa força nos antros etneos e com grande estridência sacodem as negras cavernas.

(Rusticatio mexicana, 1. 7, vv. 112-127; p. 80)

Esta semelhança entre os fossores e os Ciclopes recorda o símile entre os escravos e os Mirmidões no Brasilienses Aurifodinae (cf. vv. 935-940):

Genus exhibet aemula nigrum
Myrmidonum, dum subterranea in horrea portat
Pars onerata cibos, Longo velut agmine facto,
Pars oneranda redit, portandumque altera pondus
Pars secat: assiduum Domino stimulante Laborem
Haud secus Afros Myrmidonas nulla otia tardant.

A raça negra mostra-se rival dos Mirmidões, enquanto faz o transporte nos armazéns subterrâneos. Uma parte deve levar os pratos, como numa comprida fileira organizada, outra parte, ao voltar para trás, deve trazê-los e a outra parte separa a quantidade que é para transportar - com um capataz que os instiga, não há nenhum momento de descanso que retarde os Mirmidões africanos no seu trabalho contínuo.

(Brasilienses aurifodinae, vv. 935-940.)

A insegurança e insalubridade das condições de trabalho nas minas, tornando os trabalhadores mais susceptíveis aos ataques das doenças e aos riscos dos acidentes, não passam sem menção. ${ }^{14}$ Bartakovics, tal como fez Le Febvre e fará Basílio da Gama, sublinha a influência maligna da atmosfera viciada pelas emanações venenosas na saúde dos mineiros (cf. Metallurgicon, pp. 10, 16-17, 42; Aurum, vv. 159-172, pp. 215-216; Brasilienses aurifodinae, vv. $1215-1221$ e $1238-1252$ ).

Também Landívar segue de perto a via do Metallurgicon, notando que os mineiros eram vulgarmente afectados por doenças do tracto respiratório,

${ }^{14}$ Cf., sobre as exigências e condicionalismos da actividade mineira, A. Russell-Wood 1989: 547-600 e também P. Bakewell 1989: 105-151. 
resultantes das elevadas concentrações de gases venenosos no interior das minas (v. Rusticatio mexicana, 1. 7, vv. 69-90, pp. 78-79), mesmo se não se alonga em detalhes acerca dos efeitos da doença - que aparece identificada como silicose no Brasilienses aurifodinae - nem indica como paliativo o trabalho por turnos, como faz Basílio da Gama (cf. Brasilienses aurifodinae, vv. 1253-1276); na Rusticatio mexicana, há apenas um caminho aberto aos mineiros para escapar a uma morte iminente e inevitável, que é a de se subtraírem rapidamente à exposição aos gases, albergando-se longe das minas (cf. Rusticatio mexicana, 1 . 7, vv. 136-150, p. 81).

Se o trabalho mineiro é geralmente descrito em termos pouco lisonjeiros, pela exigência de verdadeiros titãs para o realizar, parece que a adopção dos exemplos precoces da tecnologia mineira poderia fazer muito pela melhoria das condições de trabalho que existiam no interior das minas, aumentando a sua produtividade e o lucro consequente. Numa das mais relevantes passagens do seu texto, Bartakovics descreve vários dispositivos, numa espécie de ekphrasis técnica, cujo protótipo literário se encontra no arado mencionado por Virgílio nas Geórgicas 1. vv. 169-175. Um dos exemplos é uma avançada máquina a vapor (machina Hydraulica ignea, abenea moles), utilizada para drenar as minas das inundações a que estavam sujeitas com frequência (Metallurgicon, pp. 40-41); outro, uma bomba de ar destinada a ventilar as galerias (i.e., machina anemica, sive ventosa, cf. Metallurgicon, pp. 38-39). ${ }^{15}$

Também na Rusticatio mexicana, para além da força directa que os mineiros são obrigados a despender, para transportar o mineral aos ombros do fundo da mina, o poeta menciona a existência de escadas e o recurso a uma máquina que eleva até à superfície as sacolas de couro carregadas com o minério, movida com a ajuda de duas mulas (1. 7, v. 199). Quando era necessário fazer face aos mananciais aquáticos frequentes no interior das minas, poder-se-ia optar por várias soluções, como nos diz Landívar. Encerrar a caverna (1. 7, vv. 218-227, pp. 83-4) ou fazer uma perfuração, para que as águas saíssem por impulso próprio para o exterior (1. 7, vv. 228-235, p. 84), ou então escavar grandes fossas para reunir os caudais (1.7, vv. 236-241, p. 84). A água era extraída destas cavidades com um engenho que era colocado na abertura superior da mina: as sítulas (1. 7, v. 244), conforme lhes chama o poeta guatemalteco, que eram certamente bombas, também movidas a tracção animal; Basílio da Gama descreve pormenorizadamente também estas bombas, ao longo de 39 versos, no Brasilienses aurifodinae (cf. vv. 840-879).

Podemos afirmar que, enquanto no poema Aurum a ficção e a mitologia ocupam lugar relevante, nos restantes poemas Metallurgicon, Brasilienses aurifodinae e Rusticatio mexicana,- editados já a partir de meados de Setecentos - a ficção e a mitologia seguem a par com os avanços tecnológicos da época. Não é possível mencionar aqui, pela necessária brevidade das comunicações, o conjunto de obras de referência que, quer Bartakovics, quer Basílio da Gama,

${ }^{15}$ Muito semelhante à que é descrita por Athanasius Kircher, no livro 10 de Mundus subterraneus (Amsterdam, 1665). 
quer Landívar, citam nos seus poemas, procurando, desta forma, atribuir aos seus poemas a legitimidade da ciência da época. ${ }^{16}$

Todos os poetas evidenciam a sua preocupação com o rigor dos detalhes e a veracidade do que decidiram incluir nos seus relatos, enquanto procuram conciliar a sabedoria clássica com o emergente conhecimento científico. Em concordância com o espírito do tempo em que viveram, a sua produção literária exibe profundas preocupações de utilidade científica e prática, bem como de resistência aos testes da experiência. Estas fontes poderiam fundamentar interpretações concordantes com os objectivos de produção erudita dos autores, com o espírito de emulação das autoridades a que prestaram reconhecimento e com a intenção de firme enraizamento na cultura intelectual do humanismo jesuítico.

Em jeito de conclusão, propomos a ideia que consiste na possibilidade dos trabalhos que congregámos para esta análise poderem ser usados como ilustração do constante fascínio pelo metal amarelo que surge mesmo entre aqueles de quem menos suspeitaríamos, ao supô-los mais interessados em riquezas espirituais; que esse fascínio foi motivação para vários empreendimentos académicos por parte de alguns dos muitos escritores da Companhia de Jesus; que, em especial, nos recessos desta corporação teocrática, demonstrações de proficiência nas diversas abordagens do vil metal, desde as práticas de prospecção, mineração e utilização económica até à moral das suas transacções, fossem consideradas relevantes e dignas de investigação; e, finalmente, que mesmo na 'ciência' das minas de ouro, os Jesuítas tenham buscado destacar-se como pedagogos e educadores, tal como fizeram noutras áreas de saber.

${ }^{16}$ A já referida obra Kircher é a mais citada. Bartakovics remete para obras de história, história natural e geografia de autores clássicos, renascentistas e modernos, de que podemos destacar a enciclopédia Naturalis historia de Plínio; a História natural y moral de las Indias do jesuíta José de Acosta; a Geographica orbis notitia do jesuíta Georges Fournier; ou a Epitome rerum ungaricum do dominicano Petrus Ranzanus. No caso de Basílio da Gama, as fontes clássicas de maior relevância são Ovídio, Virgílio e Horácio, respectivamente Metamorfoses, Geórgicas e Arte Poética. Do período moderno, é possível destacar modelos como a Óptica de Newton, a enciclopédia de Chambers, os Principia de Descartes e o De Revolutionibus orbium coelestium de Copérnico, por exemplo. Cf., a este propósito, A. Mariano 2005, Vol. 1: 144-153. Quanto a Landívar, além de poetas latinos como Horácio e Lucrécio, a lista compreende outras referências como, por exemplo, Sor Juana Inés de la Cruz; William Robertson (Historia de América); Ambrosio Calepino (Diccionario de la Lengua Latina); Jacopo Facciolati (Dictionarium undecim linguarum); Francisco Hernández (Historia de las aves de Nueva España); Jacques Bomare (Dictionnaire raisonné universel d'Histoire naturelle). Cita o Journal de Trérvoux (out. 1712). Menciona também um conjunto considerável de autores e obras jesuítas coevas como por exemplo: Diego José Abad (De Deo); Francisco Xavier Alegre (Traducción de la Ilíada al latín y la Alexandriada); José de Acosta (Historia Natural y Moral de las Indias), Juan Antonio de Oviedo (Zodiacum Marianum) e Jacques Vanière (Praedium Rusticum). Por outro lado, sabe-se que eram bem conhecidas nas colónias americanas espanholas no século XVIII as obras de autores como Descartes; Newton; Leibniz; Locke; Gassendi; Voltaire; Rousseau; d'Alembert entre outros. 
Bibliografia

Peter Bakewell (1989), "Mining in Colonial Spanish America", in Leslie Bethell (ed.), The Cambridge History of Latin America, vol. 2: Colonial Latin America. Cambridge, New York, Melbourne: Cambridge University Press, 105-151.

Josephus Bartakovics (1478), Metallurgicon, sive de cultura fodinarum auri et argenti carmen. Adjectus indiculus vocabulorum quorundam ad aurariam argentariamque spectantium. Latine, bungarice et germanice. Tyrnaviae: Ex. Typ. Academicis Soc. Jesu.

Vania Pinheiro Chaves (2000), O Despertar do Génio Brasileiro: Uma Leitura de "O Uraguai" de José Basílio da Gama. Campinas, São Paulo: Editora da Unicamp.

José Basílio da Gama Brasilienses Aurifodinae Poemate Didascalico Ab Aurifodinensibus Musis depromptae, sive De Auro, ejusque extractione in Brasilia Poetica Descriptio A Josepho Basilio Gama elucubrata. additis, Et Compendiaria appendice, soluta oratione: Et curiosa quaestione de Auri genesi. Mss. privado; Roma [?], 1760-1762 [?].

Steven Harris (2000), "Mapping Jesuit Science: The Role of Travel in the Geography of Knowledge", in John W. O'Malley et al. (eds.), The Jesuits: Cultures, Sciences, and the Arts, 1540-1773. Toronto: University of Toronto Press, 228-229.

Yasmin Annabel Haskell (2003), Loyola's Bees: Ideology and Industry in Jesuit Latin Didactic Poetry. Oxford: Oxford University Press, 2003.

Andrew Laird (2006), The Epic of America: An Introduction to Rafael Landivar and the Rusticatio Mexicana, London: Duckworth.

Landívar (1782), Rusticatio mexicana, editio altera auctior, et emendatior, Bononiae: Ex Typographia S. Thomae Aquinatis.

François Antoine Le Febvre "Aurum" (Paris, 1703) in François Oudin, SJ, Poemata didascalica nunc primum vel edita vel collecta studiis Fr. Oudin, Vol. 1. Parisiis: Petrum Aegidium le Mercier, 1749, pp. 210-223.

Serafim Leite História da Companbia de Jesus no Brasil, 10 vols. Lisboa: Livraria Portugália; Rio de Janeiro: Civilização Brasileira, 1938-1950.

Alexandra de Brito Mariano (2005), Brasilienses aurifodinae. O ouro e a literatura didáctica no Brasil Setecentista, 2 vols. [Tese de doutoramento, Universidade do Algarve].

A.J. R. Russell-Wood (1989), "Colonial Brazil: The Gold Cycle, c. 1690-1750" in Leslie Bethell (ed.), The Cambridge History of Latin America, vol. 2: Colonial Latin America. Cambridge, New York, Melbourne: Cambridge University Press, 547-600.

Carlos Sommervogel et al. (eds.), Bibliothéque de la Compagnie de Jésus, 12 vols.. Brussels: Oscar Schepens; Paris: Alphonse Picard, 1890-1932.

Françoise Waquet (2002), Latin or the Empire of a Sign: From the Sixteenth to the Twentieth Centuries. London \& New York: Verso. 